\title{
ERRATA
}

\section{The Shape of an X-ray Line}

\author{
By Archer Hoyt \\ Department of Physics, Cornell University
}

(Phys. Rev. 40, 477, 1932)

It has been called to the author's attention that there are two errors in Table I of the article by the above title.

Spencer ${ }^{1}$ has been misquoted. The values published for half-maximum halfwidths are in reality half-maximum full-widths. The values for Mo $K \alpha_{1}$ and $\mathrm{Cu} K \alpha_{1}$ should be reduced by a factor $\frac{1}{2}$. The values which should appear in the table of half-widths at half-maximum ordinate are
for Mo $K \alpha_{1}$
$4.8 \mathrm{sec}$.
or 0.14 X.U.
for $\mathrm{Cu} K \alpha_{1}$
$10.8 \mathrm{sec}$.
or 0.305 X.U.

${ }^{1}$ Spencer Phys. Rev. 38, 630 (1931). 